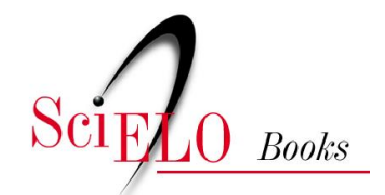

\title{
Cosmologia em maquiavel?
}

\author{
Carlo Gabriel Kszan Pancera
}

\section{SciELO Books / SciELO Livros / SciELO Libros}

PANCERA, C.G.K. Cosmologia em maquiavel? In: PINTO, F.M., and BENEVENUTO, F., comps. Filosofia, política e cosmologia: ensaios sobre o renascimento [online]. São Bernardo do Campo, SP: Editora UFABC, 2017, pp. 181-197. ISBN: 978-85-68576-93-9. https://doi.org/10.7476/9788568576939.0010.

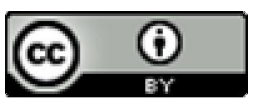

All the contents of this work, except where otherwise noted, is licensed under a Creative Commons Attribution 4.0 International license.

Todo o conteúdo deste trabalho, exceto quando houver ressalva, é publicado sob a licença Creative Commons Atribição 4.0.

Todo el contenido de esta obra, excepto donde se indique lo contrario, está bajo licencia de la licencia $\underline{\text { Creative }}$ Commons Reconocimento 4.0. 
Possui graduação em filosofia pela Universidade Federal do Paraná (1999), mestrado (2002) e doutorado (2006) em filosofia pela Universidade Federal de Minas Gerais (UFMG), com período de doutorado sanduíche na Università degli Studi di Firenze (2004/2005). Atualmente é professor de filosofia política da Universidade Federal de Minas Gerais. Tem experiência na área de História da Filosofia, com ênfase em Filosofia Política (Republicanismo e Humanismo Cívico, Maquiavel, Hobbes, Rousseau e Arendt). É autor da obra Maquiavel entre Repúblicas, publicada em 2010. 


\section{COSMOLOGIA EM MAQUIAVEL? ${ }^{1}$}

Carlo Gabriel Kszan Pancera ${ }^{2}$

Há, nos escritos teóricos de Maquiavel, um conjunto de enunciados envoltos em roupagens naturalistas e que, por isso mesmo, parecem apontar para os vínculos do autor do Príncipe e dos Discursos sobre a Primeira Década de Tito Livio ${ }^{3}$ com uma filosofia da natureza e, daí, com uma cosmologia. No capítulo de um livro não tão recente (GAILLE-NIKODIMOV, 2006, p. 227-258), um dos intérpretes da obra do pensador florentino, Jean-Yves Goffi, empenha esforços para reconstruir, a partir de tais enunciados, o que poderia ser esta cosmologia. Gostaríamos aqui de aproveitar a leitura proposta para

\footnotetext{
1 Texto apresentado no Simpósio Internacional Renascimentos - cosmologia, natureza e ética, realizado no Centro Brasileiro de Pesquisas Físicas, na cidade do Rio de Janeiro, de 09 a 11 de setembro de 2015.

2 Professor adjunto do Departamento de Filosofia da Universidade Federal de Minas Gerais (UFMG).

3 Doravante designaremos esta obra apenas de Discursos, indicando, na sequência, o livro e o capítulo; quando em parênteses, utilizaremos a letra inicial $D$, seguida do livro e do capítulo.
} 
colocarmos em questão a existência de uma tal cosmologia. Apresentaremos, então, suas teses e consequências, para, na sequência, examinarmos a pertinência de sua interpretação. Fica, no horizonte de nossa exposição, o debate acerca do estatuto da natureza no pensamento maquiaveliano, bem como sobre qual o lugar da experiência.

Goffi, no capítulo intitulado "A natureza e os céus: a cosmologia de Maquiavel", começa sua exposição chamando atenção para o caráter paradoxal de se afirmar a existência de uma cosmologia em Maquiavel, em razão mesmo das preocupações do autor, que à primeira vista dariam ocasião no máximo para se afirmar uma antropologia sumária. Do mesmo modo, a noção de natureza ali presente parece possuir um caráter meramente instrumental (GOFFI, 2006, p. 227). Para ele, esse é o caminho seguido por intérpretes como Claude Lefort, para quem o secretário florentino recusa a aceitar a ideia de um "regime conforme a essência da sociedade", portanto, conforme a natureza, e J.G.A. Pocock, segundo o qual a compreensão do pensamento maquiaveliano depende da compreensão de sua ruptura com o "universo mental e cosmológico medieval” (GOFFI, 2006, p. 228).

Jean-Yves Goffi, contudo, alinha-se a comentadores que chamam atenção para a importância do elemento cosmológico para se compreender o pensamento de Maquiavel, mesmo estando ciente do risco que corre. Ele nomeia três intérpretes que o precederam nesta tarefa, a saber: Pierre Mesnard, Eugenio Garin e Antony Parel (GOFFI, 2006, p. 228), e passa em revista suas respectivas teses.

A posição dos dois primeiros é bastante próxima. Ambos fazem da proposição acerca do movimento - um certo mobilismo universal e a férrea necessidade, em que tudo é 
movimento - o ponto central da teoria maquiaveliana e a pedra de toque para se estabelecer o fundamento metafísico do sistema. Apesar de se distanciarem nas consequências que retiram desta afirmação, igualam-se no resultado final. De um lado, Mesnard encarrega-se ele mesmo de anular a força de sua interpretação ao asseverar que o substrato real é, antes, a instabilidade política da época, o que, para Goffi (2006, p. 229), é o mesmo que afirmar que o elemento cosmológico não tem valor explicativo; de outro, Garin, depois das indicações dadas, não as explora nos trabalhos posteriores (GOFFI, 2006, p. 230).

Com Antony Parel, o caso é algo diferente, pois ele não só retoma os temas deixados à margem por Garin, como também mobiliza todo o corpus maquiaveliano, para demonstrar que "Maquiavel é tributário, no essencial, da filosofia natural tingida fortemente de astrologia de sua época" (GOFFI, 2006, p. 230-231). A ideia geral, que aí se encontra, é a de que os corpos celestes se constituem em causas gerais daquilo que ocorre no mundo sublunar; eles seriam, então, a fonte do determinismo, do destino e da necessidade invariáveis, ao passo que a fortuna referir-se-ia ao que há de aleatório no universo (GOFFI, 2006, p. 231). Segundo Goffi (2006, p. 231), Parel teria conseguido, deste modo, formular uma resposta àqueles, como, por exemplo, Strauss e Cassirer, que colocam o secretário florentino como fundador da moderna ciência política e mostrar, então, que esta posição é ilusória.

A despeito do caráter mais abrangente da interpretação proposta por Parel, ela ainda tem em comum com as duas interpretações anteriores o fato de não fazer do pensamento político maquiaveliano uma aplicação às coisas humanas de um saber de origem cosmológica (GOFFI, 2006, p. 231). 
Ou seja, não fica demonstrado por ele se o pensamento político do secretário florentino seria, e em que medida, tributário de uma cosmologia. Goffi, no entanto, insiste na importância de perseverarmos neste caminho, isto porque, segundo ele, os comentadores mencionados sugerem fortemente, por outro lado, que "a marcha das coisas humanas apenas será plenamente inteligível se tomarmos em consideração suas opções e engajamentos neste domínio" (GOFFI, 2006, p. 231). Eis, portanto, a aposta que quer fazer valer na sequência de sua argumentação.

O problema que Goffi enfrenta, e que talvez esteja na origem das disputas interpretativas já mencionadas, consiste no fato de que Maquiavel não só não formula uma cosmologia sistemática e coerente, o que coloca em dúvida a sua existência, como também parece negar que possamos fazer inferências neste sentido, pois o próprio secretário florentino, nos Discursos, I, 56, declara nada conhecer a respeito das coisas naturais e sobrenaturais. A fim de superar esta dificuldade, o intérprete em questão reexamina os vários textos do autor em que estas questões aparecem, tentando, por esta via, estabelecer aquilo que chama de cosmologia maquiaveliana.

O primeiro esforço do intérprete consiste em determinar de maneira geral o sentido do termo natureza. A despeito de suas múltiplas ocorrências na obra de $\mathrm{Maquiavel}^{4}$, o intérprete escolhe duas passagens, uma dos Discursos (D, II, 3) e outra d'O Príncipe (capítulo VII), como pontos de partida, por elas conterem a expressão "imitação da natureza". Das passagens escolhidas, é, contudo, a primeira que parece fornecer elementos adequados para seus propósitos. Ao associá-la

${ }^{4}$ O termo natura tem 127 ocorrências; natural, 5; naturale, 45 e naturali, 10. 
a outra passagem dos Discursos (D, III, 11) que enunciaria um princípio geral, conforme o qual "há em todas as coisas [...] algum mal escondido", ele infere que a natureza não pode ser compreendida somente como aquilo que é realizado por si mesmo, sem a intervenção de nenhum artifício. Isto porque, como as coisas humanas em geral, também ela traz consigo sempre algum mal inerente, uma parte obscura, precisando, de certo modo, da indústria humana. Segue-se daí que é possível dizer que a natureza comporta uma ordem, o que a torna imitável. Como, porém, esta ordem é incerta, pois está sujeita a variações abruptas e imprevisíveis, este procedimento parece encontrar um limite. Assim, a natureza parece pedir sempre a interferência da mão humana (ações virtuosas, legisladores, etc, conforme o Proêmio do livro I dos Discursos), mas, por vezes, impõe um limite à ação. Constitui-se, deste modo, numa espécie de princípio de realidade que deve servir de referência à imitação (GOFFI, 2006, p. 234).

Em suma, a natureza aparece no pensamento do florentino, de um lado, como princípio de estabilidade, que garante a repetitividade e, por conseguinte, a previsibilidade; de outro, é causa de variações brutais, o que torna o resultado da ação humana imprevisível. Concebê-la contendo tais disparidades somente é possível, segundo Goffi, por ela não ter no pensamento de Maquiavel o lugar de instância última. Por isso, o seu esforço prossegue no sentido de delimitar quais poderiam ser os elementos que constituem esta instância última, a qual indicaria qual é a ontologia maquiaveliana.

Antes de prosseguir, o intérprete em questão delimita o que está chamando de ontologia. Trata-se, para ele, de uma teoria geral sobre o ser, cujos enunciados dizem quais são os elementos últimos constituintes da realidade e como tais 
elementos se comportam. Definida assim, ele entende haver uma ontologia mínima em Maquiavel (GOFFI, 2006, p. 236). A prova de sua existência estaria numa passagem já mencionada aqui. Trata-se do capítulo 56 do livro I dos Discursos ${ }^{5}$, que cuida da previsibilidade dos grandes acidentes por adivinhos e filósofos. Nesta passagem, estariam indicados os dois elementos fundamentais de tal ontologia, a saber, as coisas naturais e sobrenaturais, embora não estivessem explícitas ali as relações entre ambas e que permanecem obscuras (apesar de apreensíveis, segundo o intérprete). Mas, por esta ontologia maquiaveliana ser mínima, ela é também incompleta.

No passo seguinte, Goffi busca precisar em que consistem estes domínios. É relevante para o caso, o Proêmio do livro I, dos Discursos. Antes de mais nada, (i) diz ele que, o secretário florentino, para além de uma certa uniformidade da natureza, estaria sugerindo que as atividades do médico, do jurista e dos atores políticos relacionam-se com uma mesma matéria, qual seja: o conflito. Prova-o, o fato de que não devem agir buscando eliminá-lo, mas apenas conformá-lo da melhor forma possível $\left(D, I I I, 1^{6}\right)$. Neste sentido, eles fazem parte de

\footnotetext{
${ }_{5}^{5} \mathrm{D}, \mathrm{I}, 56:$ "donde ei si nasca io non so, ma ei si vede per gli antichi e per gli moderni esempli, che mai venne alcuno grave acidente in um città o província, che non sia stato, o da indovini o da rivelazioni o da prodigi o da altri segni celesti, predetto. [Savonerola, etc] [...]. La cagione di questo credo sia da essere discorsa e interpretata da uomo che abbi notizia dele cose naturali e soprannaturali: il che non abbiamo noi. Pure, potrebbe essere che, sendo questo aere, come vuole alcuno filosofo, pieno di intelligenze, le quali per naturali virtù preveggendo le cose future, ed avendo compassione agli uomini, acciò si possino preparare alle difese, gli avvertiscono com simili segni. Pure, comunque e' si sia, si vede cosi essere la verità; che sempre dopo tali accidenti sopravvengono cose istraordinari e nuove alle provincie".

${ }^{6}$ D, III, 1: "Egli è cosa veríssima, come tutte le cose del mondo hanno il termine della vita loro; ma quelle vanno tutto il corso che è loro ordinato dal cielo, generalmente, che non disordinano il corpo loro, ma tengolo in modo ordinato, o che non altera, o, s'egli altera, è a salute, e non a danno suo. E perché io parlo dé
} 
um mesmo domínio; no caso, o domínio das coisas naturais (GOFFI, 2006, p. 237 - 238). Depois, (ii) é uma ontologia incompleta porque não abrange todos os tipos de "coisas naturais", limitando-se a algumas, os afazeres humanos. É suficiente, portanto, dizer que estes têm a ver com os corpos celestes e conhecer os modos de ação no domínio das coisas humanas. Maquiavel, deste modo, politiza o domínio das coisas naturais (GOFFI, 2006, p. 238). Enfim, (iii) nota o intérprete que Maquiavel, além de enumerar os elementos de que se compõem sua ontologia, precisa também seu modo de ação: movimento, ordem e potência (D, I, Proêmio). Este é um universo no qual as potências se movem, se chocam e assumem diferentes configurações (GOFFI, 2006, p. 238).

Goffi se detém ainda nos modos de ação dos elementos enumerados no Proêmio do livro I dos Discursos. Esta passagem é importante para sua construção, pois é o que vai lhe permitir afirmar a existência de um certo arranjo entre os elementos de que são compostas as coisas naturais e as sobrenaturais. Ele toma por base o termo ordini (ordem, ordenação) e o aplica aos elementos enumerados na própria passagem. Este expediente lhe permite afirmar que a disposição dos elementos ali contida reflete, de fato, uma hierarquia dos elementos de uma cosmologia, na qual dois dos níveis são ambíguos por possuírem uma dupla natureza (GOFFI, 2006, p. 239). $\mathrm{O}$ intérprete refere-se ao caso dos homens, pois se situam na fronteira entre os afazeres humanos e as coisas naturais, e dos corpos celestes, pois se encontram no limite entre o campo natural com o sobrenatural.

corpo misti, come sono le republiche e le sètte, dico che quelle alterazioni sono a salute, che le riducano inverso i principii loro". 
O pertencimento do homem à ordem natural se dá pelo seu corpo, a despeito mesmo de ser capaz de criar no interior da ordem natural um lugar de artifício (GOFFI, 2006, p. 239). Há um perspectivismo aqui: para o médico, o homem é um conjunto de órgãos; para o jurista, é um indivíduo propriamente falando; para príncipes e governantes, os homens fazem parte de um corpo misto, que são os principados e as repúblicas (GOFFI, 2006, p. 239-240). Em todos estes casos, porém, os homens estão submetidos às mesmas leis naturais dos seres vivos, que, para durarem, precisam do artifício humano (D, III, 1).

No caso dos corpos celestes, sua dupla natureza é explicada pelo intérprete do seguinte modo: i. "como última coisa natural, é o limite extremo do mundo, a esfera das estrelas"; ii. "como primeira coisa sobrenatural, é a habitação desta potência oculta que não quer o bem dos homens" (GOFFI, 2006, p. 241). O poema de Maquiavel, Capítulo sobre a Ambição ${ }^{7}$, é relevante para esta conclusão. As duas fúrias - Ambição e Avareza - ali descritas são as potências que causam a devastação do mundo e, ao fazerem isso, privam os homens de paz e de repouso. Elas irrompem no mundo sublunar para estremecer o arranjo geral do universo. Isto tudo ganharia expressão no vocabulário maquiaveliano na noção de necessidade (GOFFI, 2006, p. 243).

Segundo Goffi, a necessidade pode ser compreendida como uma força cósmica universal que se situa na junção entre as coisas naturais e sobrenaturais. De um lado, é ela que garante a regularidade do mundo, mas, de outro, "é a

\footnotetext{
7 "Di poco avea Dio fato le stelle,/el ciel, la luce, le elementi e l'uomo,/dominator di tante cose belle".
} 
potência que faz com que, para os homens, nada seja perfeitamente estável, nada seja definitivo e nenhuma propriedade esteja garantida para sempre" (GOFFI, 2006, p. 243). Ela se manifesta aos homens, às vezes, por meio da constituição das coisas naturais. Mas, por vezes, se manifesta nos afazeres humanos e no domínio da história, sem, contudo, imprimir um sentido determinado e fatal, em razão das diferenças entre os mundos supralunar e sublunar. Do exposto, vê-se que a necessidade, força de origem supralunar, afeta as coisas humanas e a história. Fica, porém, a questão de se saber em que medida isto acontece.

O primeiro passo para tornar explícito o modo como a necessidade afeta as coisas humanas diz respeito ao tema da eternidade do mundo, presente nos Discursos, II, 5. Segundo Goffi, Maquiavel afirma aí a existência do mundo por toda a eternidade, apesar de suas configurações variarem. Eterno aqui significa perpétuo, sem começo nem fim. Tem-se, então, um mundo eterno e, correspondentemente, um ser humano eterno (nunca houve um primeiro homem). Aparentemente, encontram-se separados. O passo seguinte é demonstrar que há uma relação entre eles, o que pode ser feito pela simples constatação de que os afazeres humanos são afetados pelos caprichos da fortuna. Por fim, o intérprete busca determinar, de modo mais preciso, como se pode conceber a relação entre mundo eterno e afazeres humanos (GOFFI, 2006, p. 247).

A resposta mais simples e rápida é a de um determinismo estrito segundo o qual os homens estariam na dependência direta dos corpos celestes (GOFFI, 2006, p. 247). O intérprete consegue reconhecer traços dele em certas passagens do poema O Asno, nos Capítulos e, também, na Primeira Decenal. Tal determinismo abarcaria indivíduos e seres coletivos mistos. 
Este modo de compreender a influência de um nível cosmológico em outro sugere, segundo Goffi (2006, p. 248), uma adesão de Maquiavel a uma concepção astrológica do mundo. Assim, o intérprete parece apostar de fato na adesão de Maquiavel a uma concepção de mundo de caráter astrológico, o que, nos diz ele, torna a resposta mais complexa do que nos fizeram pensar um pouco antes. Isto acontece porque a astrologia, tal como pensada no período, era uma ciência que se subdividia em astrologia genetliaquica e astrologia universal, aquela tendo por objeto as matérias individualizadas e, esta, povos inteiros (GOFFI, 2006, p. 248- 249). Tal modo de tratar as coisas teria tido reflexo no próprio pensamento de Maquiavel; o intérprete chega a evocar o capítulo XXV do Príncipe, intitulado "o quanto pode a Fortuna nas coisas humanas e como é possível resistir a ela”, para prová-lo, pois o autor parece aí seguir, tanto na estrutura, quanto no tratamento dos temas, justamente a divisão entre as espécies de ciência astrológica, bem como o modo delas conceberem os respectivos objetos. Seguindo tal concepção, conclui o intérprete que:

Os homens tomados individualmente não podem nada contra a qualidade dos tempos ... Mas, tomados coletivamente, são capazes de adotar os modos e ordens de modo que as bruscas transformações que caracteriza os afazeres humanos não os deixem desprovidos" (GOFFI, 2006, p. 250).

Deste modo, é seguro dizer que os corpos celestes não são todo-poderosos relativamente à história (GOFFI, 2006, p. 251). Se, portanto, o movimento dos corpos celestes não é determinante nas coisas humanas, é preciso, contudo, explicar o porquê de Maquiavel, no proêmio do livro II dos Discursos, apostar aparentemente numa compreensão da história 
como universal, regida por forças externas ao mundo humano. A dúvida parece pertinente, pois ali a virtude é apresentada como uma propriedade objetiva do mundo, onde haveria sempre uma certa proporção de bem e de mal, que variaria localmente, sendo distribuída diversamente entre as repúblicas e estados, mas, globalmente, seria sempre a mesma. Supõe-se, então, que a distribuição seja regrada pelo movimento dos astros (GOFFI, 2006, p. 251-252).

Admitir isso seria admitir que a hipótese avançada acima, a de que os corpos celestes não são todo-poderosos na determinação das coisas humanas, não tem efetividade. Assim, para comprovar sua tese, Goffi se vê obrigado a recorrer a Arte da Guerra (Livro 2), não só para relativizar o argumento astrológico que dá suporte à ideia de uma história universal, como também para compreender-lhe o estatuto. O intérprete chama atenção para o fato de que no fragmento em questão a explicação do movimento de ascensão e declínio dos estados nos é dada não mais pelos astros, mas pela lógica do império (GOFFI, 2006, p. 253). O princípio que está operando é o seguinte: diante da necessidade de se protegerem, os homens cultivam a virtude; uma vez que tal necessidade desaparece, a própria virtude entra em declínio; os estados, então, tornam-se presas mais fáceis de outros estados de maior virtude (GOFFI, 2006, p. 251-252). A explicação, portanto, é de caráter causal e político, mas não astrológico; o vocabulário perpétuo dos astros não tem aqui nenhuma presença e função e, de resto, Maquiavel permanece indiferente a este tipo de explicação quando trata das coisas humanas (GOFFI, 2006, p. 253).

Isto quase leva Goffi (2006, p. 254) à conclusão de que esta cosmologia de Maquiavel que ele tanto se empenhara em construir não tem nenhum papel efetivo. Ciente deste risco, 
ele procura salvar seu esforço por meio da reconfiguração do estatuto do discurso astrológico/cosmológico. Retoma, então, no capítulo 5 do livro II dos Discursos, que trata da eternidade do mundo. Interessa ao seu argumento a questão da perda da memória de tempos passados, cujas causas ou são humanas (transformações nas seitas e línguas) ou são celestes (peste, fome e/ou inundações). Segundo o intérprete, são causas complementares e convergentes. Primeiro, porque denunciam o cristianismo como uma destruição deliberada dos valores pagãos e fazem do dilúvio um fenômeno cíclico (GOFFI, 2006, p. 255); depois, porque promovem a regeneração e a purgação do mundo (GOFFI, 2006, p. 257). O que distinguiria seu uso seria apenas o objeto a que se aplicam: o argumento (e conceitos) cosmológico seria usado pelo Secretário florentino apenas para se opor às crenças ineptas ou absurdas, caso do cristianismo, ao passo que o argumento (e conceitos) político é usado para explicar o que de fato aconteceu historicamente. De resto, para Goffi (2006, p. 257), "Maquiavel afirma a autonomia da história”.

O resultado da leitura é surpreendente. Isto porque, no final das contas, resta muito pouco a ser explicado por esta suposta cosmologia/astrologia maquiaveliana. Afora alguns enunciados de roupagem naturalista-cosmológica, ao meu ver, de estatuto indefinido, tal cosmologia não tem, como o próprio Goffi anunciava, muita efetividade no âmbito de sua teoria política, que é o que mobiliza todo o esforço do secretário florentino. Seja como for, a surpresa é provocativa e nos pede algumas considerações.

A primeira delas diz respeito à motivação do intérprete, que é a de tornar claro o modo como Maquiavel pensa os efeitos dos corpos celestes no domínio das coisas humanas 
(GOFFI, 2006, p. 231). A consideração que faço aqui diz respeito à rapidez com que esta via se apresenta para ele. Isto porque no modo que formula a questão já supõe a necessidade de uma cosmologia e, então, o caminho seguido por ele de reconstrução de tal cosmologia parece natural ou necessário. Mas seria de se esperar que tecesse algumas considerações sobre o eventual estatuto retórico ou de linguagem corrente que tais enunciados poderiam revelar.

Quanto ao caráter de linguagem corrente, deve-se notar inicialmente que os temas tratados no artigo, principalmente as questões relativas à astrologia, faziam parte do mundo cultural no qual vivia o secretário florentino. Seria perfeitamente compreensível, então, que ele utilizasse tais termos para expor suas ideias, sem que estivesse formulando necessariamente uma cosmologia. Isso poderia explicar, por um lado, não só a presença dos referidos temas como também a falta de articulação entre os diversos enunciados deste caráter contidos nos seus escritos; de outro lado, esta hipótese talvez conservasse maior consonância com os propósitos da obra maquiaveliana, que têm em vista questões quase exclusivamente de natureza política.

Quanto ao eventual caráter retórico dos enunciados, deve-se lembrar o fato de que Maquiavel dominava bastante bem o instrumental retórico dos autores clássicos, em especial os de Cícero e Quintiliano, e os mobilizava frequentemente para subverter as teses correntes opostas às suas. No caso bastante conhecido dos capítulos XV a XVIII, do Príncipe, reconhecemos facilmente a utilização da paradiástole (Skinner, 2002). Não é difícil, porém, encontrar em momentos diversos da sua obra a utilização de tal instrumental. E justamente o capítulo 56, do livro I, dos Discursos, frequentemente utilizado pelo autor em questão, parece ilustrar bem o modo de proceder do pensador florentino. 
Já o título do capítulo parece sugerir a adesão do autor à possibilidade de se ler sinais que antecipem o acontecimento de grandes acidentes. Ora, na sequência do texto ele retoma esta possibilidade para, por fim, esvaziá-la de todo sentido; primeiro, dizendo nada saber de tais coisas, depois, fazendo uma constatação de natureza política: aos tais acidentes sucedem grandes inovações (do ponto de vista político, a única coisa que pode ser prevista!). O surpreendente é que justamente daí Goffi enxerga indícios de uma cosmologia mínima, quando o que mais certamente poderia ser dito é que Maquiavel sabia que circulava em Florença, em especial, nos participantes dos Orti Oricellari, um discurso de caráter astrológico/cosmológico e o mobiliza para conseguir atenção e adesão a suas teses.

A despeito disso, Goffi envereda na construção desta cosmologia maquiaveliana. Para fazê-lo, ele se vê obrigado a lançar mão de alguns expedientes que obrigam o texto a dizer mais do que ele permite dizer. O principal é o reconhecimento de uma hierarquia entre os elementos enumerados no Proêmio do livro I dos Discursos, sem a qual seu argumento não pode subsistir. É duvidoso que, para além de um exemplo de regularidade na história, o texto dê sustentação a esta inferência, de modo que uma das pedras de toque de sua interpretação parece bastante frágil.

No nosso entender, o que me parece que o intérprete faz é projetar no pensamento do secretário florentino uma concepção cosmológica corrente na época, cujos enunciados fazem parte do senso comum e, nesta condição, respingam no texto do secretário florentino (averroísmo, astrologia, etc.). Mas, chamo atenção, respingam com este estatuto, isto é, como vocabulário do senso comum, não como formulação cosmológica mínima. Nesta linha, a descrição de Goffi é útil 
justamente por reconstruir parte do ambiente cultural no qual Maquiavel se inseria e que se encontrava eivado de astrologia e do aristotelismo radical de Averróis. Pode-se dizer, então, que ele lê o texto maquiaveliano quase em continuidade com a tradição, no caso a de uma filosofia da natureza ou cosmologia e, assim, perde de vista o caráter subversivo do autor, que, para falar o mínimo, nos coloca em alerta para as eventuais continuidades. Em suma, o que parece fazer Goffi é, na feliz expressão de um colega de trabalho, construir uma cosmologia para Maquiavel e não uma cosmologia de Maquiavel.

\section{Referências}

GOFFI, Jean-Yves. "La Nature e les cieux: la cosmologie de Machiavel". In: GAILLE-NIKODIMOV, Marie (Org.). Lectures sur Machiavel. Paris: Ellipses, 2006. p. 227-258.

MACHIAVELLI, N. Opere, a cura di Corrado Vivanti. Torino: Einaudi-Gallimard, 1997.

PAREL, Antony. "Human Motions and Celestial Motions in Machiavelli's Historiography”.I In: MARCHAND, J. J. (Org.) Niccolò Machiavelli. Politico, Storico, Letterato. Atti del Convegno di Losanna 27-30 settembre 1995. Roma: Salerno, 1996.

POCOCK, J. G. A. Politics, Language and Time. Essays on Political Thought and History. New York: Atheneum, 1971.

SKINNER, Quentin. Visions of Politics. Vol. 1: Regarding Method. Cambridge: Cambridge University Press, 2002. 